\title{
The career goals of nurses in some health care settings in Gauteng
}

\author{
K Jooste, D Litt et Phil \\ Associate Professor, School of Nursing, University of Johannesburg
}

\section{Keywords:}

Career, goals, management, development

\section{Abstract: Curationis 28(3): 47-53}

In nursing, purposeful career planning is essential if nurse practitioners want to make the right decisions about their work in order to strive towards and accomplish a meaningful quality of working life. Nurses should identify their career goals to be able to investigate their different career opportunities in their field of interest and direct their work according to a work strategy for years ahead. The purpose of this study was to explore and describe the career goals of post-basic nursing students with the aim of describing management strategies to guide the future career of post-basic nursing students in climbing the career ladder effectively and obtaining their set career goals.

An explorative, descriptive, qualitative design was selected where the researcher worked inductively to explore and describe the needs (goals) and future planned actions of the participants regarding their career management as viewed for a period of five years.

The researcher purposively and conveniently identified the sample as all the postbasic nursing students, namely 250 students, who were registered for the first, second and third year of nursing management courses in that period at a South African residential university. Two structured, open questions were developed. Each participant received the questions in writing and was asked to answer them. The QSR NUD*IST program was used for the qualitative management (categorization) of data.

The results of the research questions related to five categories, namely becoming empowered, being promoted, being educated and professionally developed, partaking in research and taking up new projects.

\section{Introduction and background}

In the past few years, national health systems in different countries have been subject to a reconfiguration of services as downsizing or rightsizing has led to the creation of flatter organizations. Developments in health care (the growth of community care and the expansion of primary care) are likely to continue this process and the health professions have already begun to explore the possible implications of these changes for the future. Changes in service delivery have centred on care delivery, and clinical and managerial structures and systems needed to plan, manage and support it. Less has been heard about the human implications of such changes, which could be traumatic for those involved. Moreover, almost all the attention has been directed towards the impact on those professionals who remain in new managerial roles of a general or project management nature. There has also been almost no focus on those people who are forced to adapt their employment relationship with the National Health System due to downsizing in human resources (Edmonstone \& Watt, 1995:17). The necessity for career planning is thus evident.

One can define career lines as "given, standardized sequences of positions that are specified by organizations in a formalized way for particular groups of 
employees and which are related to persons, but independent of the individual. Such normative frameworks for sequences of positions are preferably found in large organizations and bureaucracies" (Nachbauer \& Riedl, 2002:716). However, the responsibility for career management lies both with the individuals and the organizations that employ them (Orpen. 1994:27).

\section{Problem statement}

During the course of teaching nursing students the subject of nursing management, the researcher became aware that students had no focus on what they were moving towards in the next five year of their career. Their future career paths had not been established. The researcher thus became aware that postbasic nurses are unclear about their future objectives and how to take action to manage their own careers. The role of career management cannot be overemphasized in this climate where nurses must make the right decision to obtain a satisfactory work and career life.

The research question that came to the fore was how focused nurses were in climbing the career ladder.

\section{Literature review}

Authors focus on different phases and steps in career management that are essential to become a well-balanced, satisfied and successful employee. In nursing, the lack of effective career management could have negative consequences for individual nurses and could for example lead to demotivation and stagnation in their nursing practice, with implications for quality nursing care.

The first step in career management is career examination (Wilson, 2002:36). When you have examined your career, you should be able to answer the questions: "Where am Inow?" and "How did I get here?". Based on your examination. you should evaluate career choices that reflect your interest.

When most people think about the future, they have in mind some things they want to accomplish during their lifetime or career. The greatest difficulties in getting what we want in our career are, firstly, establishing what we really want and, secondly, taking the step to write down our dreams and goals. This is the next step to learning what you want in your career. and in what order of importance you want to accomplish these goals (Linney, 1995:2).

Careers in organizations are meant to be planned and managed in a joint manner, and a system is designed to answer the needs and requirements of both the individual and the organization. The fit between organizational and individual needs is at the core of the careers model (Baruch. 2003:249).

\section{Purpose of the study}

This study led to the identification of broad strategies for nursing managers to guide the future career management of post-basic nursing students in climbing the career ladder effectively and obtaining their set career goals.

\section{Aims of the study}

This study aimed to explore and describe:

- the goals that post-basic students set in planning their career for a period of five years;

- the actions needed to obtain students' set goals; and

- $\quad$ strategies to guide the future career management of postbasic nursing students on how they could climb the career ladder effectively and obtain their set career goals.

This article mainly focuses on the first objective, namely the goals that students set in planning their career.

\section{Key concepts}

The two main key concepts that need to be defined are career management and post-basic nurses.

\section{Career management}

In the literature, career lines and careers are either distinguished as independent concepts or used as synonyms (Nachbauer \& Riedl, 2002:720). The term career management refers to a process that links a nurse's objectives (goals) and aspirations (planned actions) to her future career growth.

\section{Post-basic nurses}

For the purposes of this study, the term post-basic nurse refers to a nurse registered with the South African Nursing Council as a professional nurse and who has undertaken further studies in postbasic courses.

\section{Design and method}

An explorative, descriptive research design was selected (Burns \& Grove.
1993:28-29) where the researcher worked inductively to explore and describe the goals and planned actions of the participants regarding their career management as viewed for a period of five years.

The study on career management was undertaken among post basic, undergraduate nursing students registered for the courses in Professional Nursing Science at a South African residential university.

\section{Population and sampling}

Approximately 250 respondents represented the population of nursing students that were registered for a postbasic nursing programme in a residential university in Gauteng for the first semester courses in Professional Nursing Science (nursing management).

The researcher purposively and conveniently identified the sample as all the post-basic nursing students, namely 250 students, who were registered for the first, second and third year of nursing management courses in that period. A purposive sample was undertaken were participants rich in information, being registered professional nurses, were selected (Morse, 1994:91). Students were asked to participate voluntarily in the study and 198 students of the sample indicated their willingness to participate, and were therefore included in the research project.

\section{Data collection}

Two structured, open questions were developed. Each participant received the questions in writing and was asked to answer them.

The following two questions were presented to the participants:

- Which career goals do you want to achieve in the next five years?

- What actions are you going to unciertake to achieve these set objectives?

\section{Data analysis}

The QSR NUD*IST program was used for the qualitative analysis (categorization) of data. The responses to the questions were analyzed separately. The following steps and principles of Tesch (in Creswell, 1994:154155 ) were followed in the data analysis:

- $\quad$ All the responses on the 
objectives and actions were read separately to form an idea of the career management ideas of post-basic nurses.

The researcher thought about the underlying meanings and wrote notes in the margin. All similar topics were clustered together under major topics.

- $\quad$ Coding was done.

- $\quad$ The most descriptive wording for topics was converted into categories.

The researcher interpreted the results to elicit the meanings that emerged from the data. This enabled the researcher to identify and describe the objectives and necessary actions for career management from the viewpoint of the participants. The findings were supported by a literature review after the data collection.

\section{Trustworthiness}

Trustworthiness was ensured according to the four principles of credibility. transferability, dependability and conformability (Babbie \& Mouton, 2001:277-278).

Credibility was ensured through postbasic students who were engaged in their own career management in the nursing field of practice. Consensus between the researcher and an external coder was important with regard to the categories and interpretations to be arrived at, from the data collected.

Transferability was aimed at by including post-basic students of the private and public sectors in Gauteng, working in different fields of nursing specialties. The final guidelines led to the formation of a conceptual framework that will at a later stage be discussed by an expert group of post-basic nurses/managers, for indepth interpretations of, and comments on, the research findings.

To enhance conformability, the researcher established an audit trail, by importing the personal documents into a qualitative assisting data-analysis programme, namely QSR NUD*IST 4.0. The data analysis is available in printed form, and the data as well as the researcher's interpretations were scrutinized by a colleague - an expert in qualitative data analysis.

The establishment of an audit trail enhanced the dependability of this

Table 1 Five categories of career goals set by the participants

\begin{tabular}{|l|l|}
\hline Category & Career goals for next five years \\
\hline Category 1: & Become empowered \\
\hline Category 2: & Be promoted in a conducive/motivated environment \\
\hline Category 3: & Be educationally and professionally developed \\
\hline Category 4: & Participate in research and quality care control \\
\hline Category 5: & Take up new projects inside and outside the workplace \\
\hline
\end{tabular}

project.

\section{Ethical measures}

Strict ethical measures were adhered to during this research project and the ethical standards set for research by the Faculty of Education and Nursing was adhered to. Students attending the lectures of nursing dynamics and Professional Nursing Science in postbasic courses were asked to participate in the project only after all lectures were completed, so that the participants did not feel intimidated or coerced to participate. The participants were fully informed about the advantages, the purpose and all the implications of the research project.

The participants' right to withdraw from the project at any stage was respected. Other ethical considerations were the informed consent of the participants, ensuring confidentiality and the anonymity of the participants. The results of the study will be made available to the students by means of a published article.

\section{Significance of the research project}

The participants were able to express specific and clear objectives and actions about their future career directions. Strategies and guidelines to enhance the role of a mentor for employees were formulated to lead to more effective career management and job satisfaction. Job satisfaction in the workplace leads to fulfilling institutional goals. The results are also an indication of what the needs of nurses are in terms of in-service training needs or access to data on an information system.

\section{Results}

From the data analysis, it became apparent that there were five main objectives set by the participants for the next five years (table 1 ).

\section{Category 1: To become empowered}

The participants stated the following aspects in the self-empowerment category:

\section{- "To be a good administrator and educator" \\ - $\quad$ "To develop, to be more matured in the profession, to make meaningful contributions in my unit" \\ - "Having a motivation function. to be the best advocate for $m y$ patients and to motilate staff members" \\ - $\quad$ "To have more knowledge, to manage my own unit more skilled and effectively, be knowledgeable and competent in my area of interest" \\ "Having a leadership role, to be a leader in my field".}

To be able to address the above mentioned statements, nurses should empower themselves. Employees should monitor their own opportunities in the organization. If alternatives are available, employees should consider changing the organization before qualifications and motivations are heavily affected (Nachbauer \& Riedl, 2002:729-730).

Some warning signals of disempowering structures are clearly seen at an organizational level. These include a policy of lean management, vacancies in target positions and, at a personal level. diminishing qualification opportunities, long tenure in a position, a reduction of status symbols and of interaction with important managers, and the narrowing 
of responsibility. Proactive action to promote empowered nurses is possible only if problems can be identified. Searches for actions may include talks with supervisors and the arrangement of an individual career and development plan. Direct empowering supervisors are important for guidance, but also strategic impression management and an increase in visibility, reputation and networking by employees. Other empowering actions include the redesign of individual tasks and responsibility. Here we can see the importance of organizational preconditions: all these actions must be possible within an organizational context, which has to emphasize flexibility rather than rigidity (Nachbauer \& Riedl, 2002:721).

In a personal career plan, the expansion of scope may include looking for opportunities to diversify in role, practice setting, networking or income sources. "Market entry" refers to joining a new group or professional association. Furthermore, consulting for colleagues on special projects or gaining expertise in new areas of practice may translate to new product development in the business language. Indeed, as the health professional heads toward retirement age, downsizing activities as well as financial obligations may be new priorities (O'Connor, 2004:2).

\section{Category 2: To be promoted in a conducive/motivated environment}

Many participants had the vision of obtaining a higher managerial position in their specific nursing unit, e.g:

- $\quad$ cho be a deputy/second in
- $\quad$ "to become in charge of a
trauma unit".

Some even had the vision of becoming a Nursing Service Manager or Director of a health service.

The participants wanted to move from their current position. They stated: "I want to move forward in my career" and "I want to be able to get a more senior professional post". Others stated that they wanted to move:

- $\quad$ "to a position with more involvement in management issues"

- $\quad$ towards the position of a unit manager, being in charge of her own unit", and

"to a more specialized unit".

In the common pyramid-shaped organization, virtually everyone's career at one time or another reaches a point where further hierarchical advancement is unlikely. As organizations tend to reduce their staff in lean times, through techniques such as business reengineering, downsizing and spin-off activities, further advancement within the organization becomes more unlikely, and employees have to face the fact that they have to remain in the same position longer than expected without any reduction in performance level. Beyond the problems faced by workers in large organizations, employees in small-to-medium business units, whose economic impact is still in European countries, also face a difficult situation. In these firms, vertical career movement is limited and position immobility is a normal event (Nachbauer \& Riedl, 2002:725).

The participants stated that their working conditions needed to improve in view of creating conducive working conditions.. One participant summed this up in the statement: "to have a better working environment". Aspects of incentives, status, money and job satisfaction where mentioned. Some of the respondents' statements regarding their work environment indicated concerns such as:

"To pay back contracted time
in hospital, to save money, and
to earn a sustainable salary"
"To be more financially
- $\quad$ "Independent"
"I want to have a higher salary"
"I need better working hours,
to be able to work when it suits
me", and
"I need to have power and
status".

One respondent stated: "to be able to experience the highest degree of job satisfaction". Another respondent stated that the latter could be attained through improvements in nurse-patient and employer-staff relations.

Career counseling and career agreements between employees and supervisors as well as transparency of promotion standards, often in connection with qualification programmes and assessment procedures, help to avoid disillusions on the part of the employee. Organisations are faced with increasing insecurities in an environment that is becoming more and more turbulent. For most companies, it is simply not reasonable to guarantee a career plan many years in advance. This implies a trade-off between current motivating effects brought about by career promises and later dissatisfaction because of disillusions and unmet expectations (Nachbauer \& Riedl, 2002:727). The lack of flexibility in terms of promotion and task variety leads to poor results in terms of satisfaction and commitment. This is even worse if the only perspective is to remain in the same job and task for the rest of one's working life. Individualized, flexible career systems must be preferred over standardized career systems. Flexibility can be reached not only through vertical movement, but also through horizontal development such as periodical job rotation, work in projects and task variety.

For all these reasons, it is not surprising that, apart from vertical promotion systems, the horizontal hierarchy is increasingly being introduced in the business reality. The fundamental idea of dual ladders is to create another hierarchy that comprises special ranks, titles, tasks and rewards, but does not include management functions such as responsibility for staff or resources. Typically, positions in the dual ladder have professional or technical functions. The offer of additional promotional opportunities is only one goal. Dual ladders also aim to stimulate and reward specialized functions, offering possibilities for more freedom at work, and diminishing fluctuation and the brain drain (Nachbauer \& Riedl, 2002:727).

Moreover, the more employees perceive that rewards such as recognition, promotion and bonuses are associated with their respective performance, the greater their career commitment (Cheng \& Ho, 2001:310; Orpen, 1994:34).

\section{Category 3: To be educationally and professionally developed \\ Involvement in educating others}

A key element of any career development process is management development and training (McCarthy \& Garavan, 1999:437).

Various comments stated that participants wanted to become involved in education. These include the following goals: 
"To educate nurses at basic level"

- "To act as a facilitator"

- "To become a nurse educatorl tutor at a college/university"

- "To mentor students"

- $\quad$ "To be part of an educational team at a tertiary institution", and

- $\quad$ "To be involved in clinical teaching/clinical instructor".

One respondent stated that her goal was "to be a role model for the coming generations".

Students were undertaking an educational programme and they all indicated that their main aim was to complete their current studies, i.e. a post-basic qualification (degree or diploma).

\section{Undergoing further training}

Many participants mentioned that they wanted to educate themselves further by training, working, gaining experience and specializing in different nursing fields of specialization. The fields of interest were identified as neonatal care, intensive care, nursing management, neonatology, occupational nursing, critical care nursing, advanced midwifery nursing science, and theatre technique.

The participants were also interested in following further short courses or certificates in primary health care, occupational health, immunization, tuberculosis, HIV/AIDS, family planning, resuscitation, trauma and breastfeeding.

Approximately ten per cent of the respondents indicated that they wanted to proceed with their postgraduate courses or master's degree studies to proceed to a doctoral nursing science degree.

Two participants indicated the desire to study in a field outside nursing such as human resources management and psychology. Some students indicated that they wanted to convert their certificate studies to a diploma qualification.

The commonly accepted perspective that vocational education and training precedes career advancement is no longer always true. Today, careers become a "patchwork" of jobs and continuing upward opportunities are restricted. This set of circumstances is, in most cases, neither planned nor expected by the individual. He or she can only react to these outside pressures (Nachbauer \& Riedl, 2002:727).

\section{Gaining experience}

It was interesting to note that nurses were eager to learn more, and to increase their knowledge and experience in their career. The following comments reflect their eagerness: "want to.....

\begin{tabular}{|c|c|}
\hline & $\begin{array}{l}\text { have more knowledge about } \\
\text { my profession", }\end{array}$ \\
\hline • & $\begin{array}{l}\text { learn characteristics and role } \\
\text { of a unit manager", }\end{array}$ \\
\hline$\bullet$ & $\begin{array}{l}\text { know everything about ICU } \\
\text { management", }\end{array}$ \\
\hline & $\begin{array}{l}\text { improve knowledge in } \\
\text { midwifery", }\end{array}$ \\
\hline & $\begin{array}{l}\text { become skilled in nursing", } \\
\text { and }\end{array}$ \\
\hline & $\begin{array}{l}\text { obtain all the needed } \\
\text { knowledge in my field". }\end{array}$ \\
\hline
\end{tabular}

A few respondents indicated their goal to work abroad or pursue their studies overseas. One respondent stated the possibility of emmigrating to Australia while others indicated working overseas for periods of no longer than two years and returning to South Africa.

The content level of career management and development programmes should be to ensure that employees gain experience that could be obtained through lifelong learning that is encouraged. The organization should develop a pool of highly skilled and competent individuals to meet its business goals (Levenson \& Hinrich, 2000: 11 ).

Nurse managers should take care that employees gain experience and that the context of career management and development focus on the following:

- Assess the human resources needs of the organization to identify limitations in experience

- Review the organization's structure

- $\quad$ Review the organization's culture and climate

- Develop a career management policy

- $\quad$ Help employees to assess their own potential and career needs Develop and publicize career opportunities in the organization
Align the employees' needs and abilities with career opportunities (Levenson \& Hinrich, 2000:11-12).

\section{Category 4: To participate in research and quality management}

Surprisingly, the students indicated their desire to become involved in the writing and publishing of articles and books.

The respondents set their goals on participation in research, regarding community involvement, education and clinical areas of midwifery (neonatal) as well as primary health care diseases. The aim of attending national and international congresses in e.g. theatre training and nursing management was mentioned. One participant stated: "I want to attend as many conferences as possible".

The respondents identified the need to play a role in total quality management in a service, and mentioned their role as to:

- "ensure quality nursing care",

- $\quad$ "increase standards in my unit, and to improve the quality of nursing care";

- $\quad$ "implement standards in my unit, and to provide quality nursing care"; and

- $\quad$ "be able to meet set standards".

One participant indicated that she had the goal of "developing new strategies for my working institution".

Individual employees must ultimately take responsibility for making informed choices and decisions to partake in research and total quality management, and hereby they will influence their destiny both within and beyond the organization (Levenson \& Hinrich, 2000:18).

\section{Category 5: To take up new projects inside and outside the workplace}

One way of nurturing outstanding people is to recognize that high achievers require a job that stretches their talents. New job assignments are a great means of developing people. Cross-functional moves, profit-and-loss responsibility, the chance to start a new business activity, and participation in high-profile task forces place employees in unfamiliar 
territory where they can develop new skills and grow (Edmonstone \& Watt, 1995: 19).

A career implies progression through a number of official organizational roles, with the associated titles, status and salaries. Employability means thinking not just in terms of the job skills needed to do the current job, but also about personal career management - with skills in acquiring new skills, which involves individuals asking themselves: "What do I need to learn so that I can decide what to do next?" People who develop such competencies are likely to take up new projects inside and outside the workplace because they:

- think of their career not only in a job or employment sense, but also in a more holistic "life" sense; and

- $\quad$ are highly adaptable in what they want and what they would be prepared to do inside and outside the workplace.

Ultimately, this means "de-coupling" personal identity from the job, profession or employer and seeing jobs as a means (temporary and only part of a greater life experience) and not as an end in themselves (Edmonstone \& Watt, 1995:19).

The respondents indicated their ideas of establishing new nursing projects, such as becoming computer literate, and setting up a formal psychotherapy unit in their hospital.

A few participants made the statement: "I want to become the manager of $m y$ own private practice". The following ideas were uttered: "I want to..."

- $\quad$ "obtain my oun nursing practice number to be an entrepreneur in order to create work",

- $\quad$ "find a place to render education in nursing and get accredited with the regulation bodies",

- "own a private school of nursing",

- $\quad$ "start a day' centre for adolescents",

- $\quad$ "retain and recruit nursing staff nationwide", and

- "to run a nursing agency".

Some respondents even mentioned new outside opportunities such as flower arrangements and catering.

The following comments were made: " $I$ want to..."

$$
\begin{aligned}
& \text { " } \quad \text { "move out of nursing and go } \\
& \text { and work on a ship", } \\
& \text { "be in a job other than nursing } \\
& \text { for better working hours", } \\
& \text { "further my' musical studies", } \\
& \text { and } \\
& \text { "open my' own crèche for } \\
& \text { children". }
\end{aligned}
$$

Focus was also placed on the "personal life" of the respondents. One respondent stated the importance of "establishing a balance between career, social and family life". Another stated the desire "to start a family".

The need to serve the community was a major goal by the majority of the respondents. They were of the opinion that nursing should be viewed more positively by the community. The respondents indicated that they wanted to become involved in the community through the following:

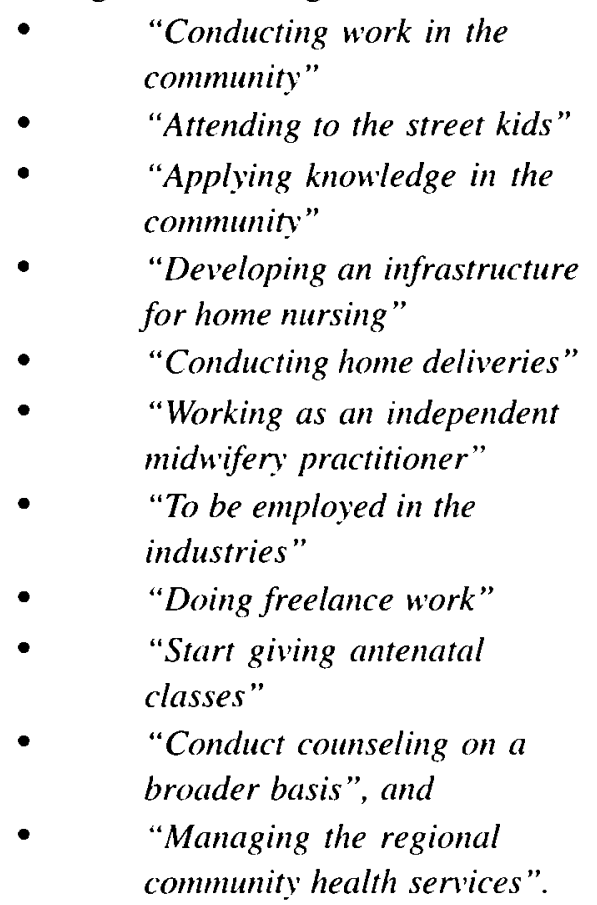

The promised traditional path provided an uninterrupted climb up the organizational ladder, job security and employee loyalty. The new and still evolving career path has been called "protean" or "boundary less" with individuals moving from company to company. The career is not directed by the organization but by the needs and values of the individual as these changes through time (Reitman \& Schneer, 2003:66).

\section{Conclusions}

The following conclusions were reached:
1. Nurses need to become empowered through strategies of self development, self motivation and developing their leadership abilities.

2. Nurses need to be promoted in a motivated environment through the availability of managerial positions, promotion opportunities and satisfactory working conditions.

3. Opportunities for educational and professional development should be known by nurses to take the responsibility to develop themselves continuously.

4. Employers should encourage nurses to undergo further training to address the needs of the community and to promote staff satisfaction.

5. Nurses have the need to gain experience in a variety of health care fields.

6. Nurses experience the need to become entrepreneurial skills in taking up new projects inside and outside the workplace.

\section{Recommendations}

The following recommendations are made for nurse managers to address the goals set by the participants:

1. Involve employees in new stimulating projects.

2. Plan for and create new types of posts, moving from a hierarchy to a network structure, using motivational strategies effectively.

3. Plan and budget to provide opportunities for employees to attend courses and conferences on a continuous and rotating basis.

4. Promote research projects and evidence-based practice that leads to publications and quality nursing care in service delivery.

5. Promote a philosophy of a productive, motivated, healthy and balanced workforce, through a people management and wellness programme for nurses.

6. Nurses should be encouraged to use nursing informatics to facilitate their career development. 


\section{Conclusion}

Nurses have specific needs in their career that they state as their goals for the future. From the findings, it becomes evident that to address career goals, both organizations and individuals should share responsibility for the careers of employees. Nurses are likely to have more successful careers, both objectively and in terms of their career experiences, if both are involved in career planning and management. Both are likely to benefit a case of where doing the right thing is also doing the effective thing (Orpen, 1994:36).

\section{References}

BABBIE, E \& MOUTON, J 2001: The practice of social research. Cape Town: Oxford.

BARUCH, Y 2003: Career systems in transition: A normative model for organizational career practices. Personal Review, 32(2): 231-251.

BURNS, N \& GROVE, SK 1993: The practice in nursing research; conducts, critique and utilization. $2^{\text {nd }}$ Edition. Philadelphia: Saunders.

CRESSWELL JW 1994: Research design: Qualitative and quantitative approaches. California: Sage.

CHENG, EWL \& DCK HO 2001: The effects of some attitudinal and organizational factors on transfer outcome. Journal of Managerial Psuchology. 13(5): $309-317$.

EDMONSTONE, J \& WATT, S 1995: Career management support for nurses. Health Manpower Management. 21(5): 17 -20 .

GREENHAUS,JH; CALLANAN, GA \& GODSHALH, VM 2000: Career management, $3^{\text {rd }}$ edition. Orlando: Harcourt.

HUBER, D 2000: Leadership and nursing care management. $2^{\text {nd }}$ edition. London: Saunders.

LEVENSON, R \& HINRICH, K 2000: Career management development. Knowledge Resource. Academia: Randburg.

LINNEY, BJ 1995: A different kind of time management. Physician Executive.
21(11):1-3.

McCARTHY, AM \& GARAVAN, TN 1999: Developing self-awareness in the managerial career development process: the value of 360-degree feedback and the MBTI. Journal of European Industrial Training. 23(9):437-445.

MORSE, JM 1994: Critical issues in qualitative research methods. London: Sage Publications.

MULLER, M 1998: Nursing dynamics. $2^{\text {nd }}$ edition. Natal: Heinemann.

NACHBAUER, AGM \& RIEDL, G 2002: Effects of concepts of career plateaus on performance, work satisfaction and commitment. International Journal of Manpower. 23(8): 716-733.

O'CONNOR, MS 2004: Strategic Planning for Career Development. JONA. 34(1): 1-3.

ORPEN, C 1994: The Effects of Organizational and Individual Career Management on Career Success. International Journal of Manpower. 15(1): 27-37.

REITMAN,F \& SCHNEER,JA 2003: The promised path: a longitudinal study of managerial careers. Journal of Managerial Psychology. 18(1): 60-75.

WILSON, M 2002: A model approach to managing your career. PT - Magazine of Phvsical Therapy. 11(3):37-39. 